\title{
Gloria Fuertes, poeta y mujer comprometida'
}

Gloria Fuertes, poet and committed women

\author{
ANTONIO A. GÓMEZ YEBRA \\ Universidad de Málaga \\ España \\ yebra@uma.es
}

(Recibido: I2-I2-2OI6; aceptado: I4-I2-20I6)

Hace 100 años nació una mujer que habría de dejarnos marcadas a varias generaciones que nos acercábamos simultáneamente a su obra, en el día a día en el que se iba produciendo. Una mujerfuerte y a la vez increiblemente tierna que miraba a la vida, a la gente, de manera directa, que luchaba y acariciaba con la palabra. Una poeta que supo hacer de la televisión un medio privilegiado para formar a los más pequeños, a la manera que Chartier reconoce en otros autores de su Francia natal en este mismo número de Álabe.

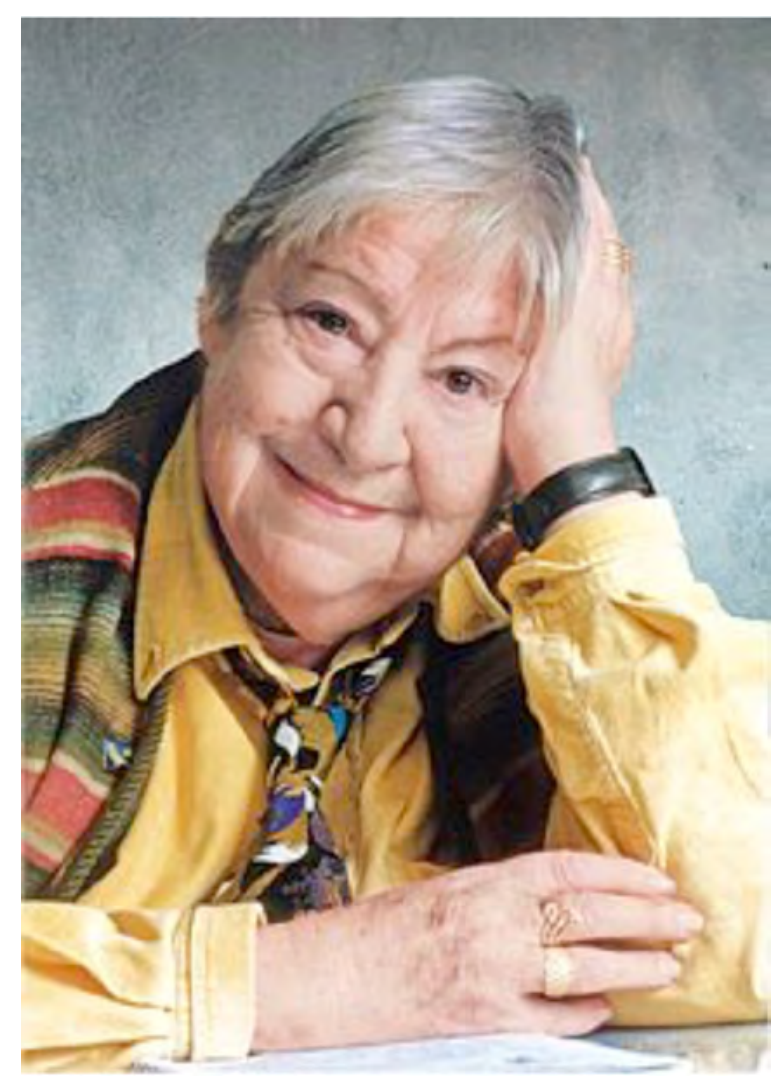

\footnotetext{
I Para citar este artículo: Gómez Yebra, Antonio (20I7). Gloria Fuertes, poeta y mujer comprometida. Alabe 15. [www.revistaalabe.com] DOI: IO.I5645/Alabe2OI7.I5.I2
} 
Aunque Gloria Fuertes suele ser conocida como la poeta de los niños, y muchos aún piensan que su dedicación a la escritura para los de menor edad lastró su obra poética para adultos, fue una de las voces más comprometidas entre 1950 -año de la publicación de su primer libro- y 1998, año de su fallecimiento en Madrid, la ciudad que la había visto nacer 8I años antes.

No era necesario que la guerra se llevara al novio con el que se iba a casar, como afirmó en alguna ocasión, para abominar de la guerra. Por eso tiene palabras demoledoras para los ejércitos y quienes hacen uso de las armas durante las contiendas. Con un lenguaje sencillo -destinado a los niños- pero directo y muy claro pese a utilizar la paradoja, definirá qué es un ejército:

\section{EJÉRCITO}

Montón de hombres armados, para defenderse atacan, al atacar matan hombres, mujeres y niños -con tiros, cañonazos o bombas-. Un hombre, si en la guerra mata a alguien, es un criminal. Un hombre, si en la guerra mata a alguien, es un héroe.

Cuando la humanidad humana se haga y use el corazón desaparecerán los ejércitos y se acabará la maldita función de la guerra.

Cuando usemos el corazón

Todos nos llevaremos bien y nos querremos un montón.

(iQue sea pronto!) ${ }^{2}$

En el mismo libro, definiendo la contaminación, se expresará con contundencia sobre el tema:

Que los hombres no manchen los ríos.

Que los hombres no manchen el mar.

Que los niños no maltraten los árboles.

Que los hombres no ensucien la ciudad.

(No quererse es lo que más contamina

sobre el barco o bajo la mina).

Que los tigres no tengan garras,

que los países no tengan guerras.

\footnotetext{
2 "Ejército", Diccionario estrafalario, pág. 48.
} 
Que los niños no maten pájaros, que los gatos no maten ratones, y sobre todo

que los hombres no maten hombres ${ }^{3}$

Su posicionamiento antibelicista (llegó a afirmar que "hay hombres más animales que los animales”) se dejó oír también en los libros destinados a los más jóvenes lectores, por eso no quiere que se les propongan armas convertidas en juguetes, una postura que se adelantó a muchos postulados semejantes:

\author{
ARMAS \\ Los juguetes son para jugar a jugar \\ (de verdad), \\ no para jugar a matar \\ (de mentira). \\ Las pistolas (ni de agua). \\ El revólver (ni de broma). \\ La escopeta (ni tocarla). \\ Los juguetes para todo \\ y las armas para nada 5 .
}

Para la guerra preparó una definición tan larga como completa:

Lo peor que sucede a la humanidad.

Hombre contra hombre, pueblo contra pueblo, nación contra nación, cientos o miles de hombres se dedican a matar a otros hombres. Epidemia de cáncer en el alma, el corazón se llena de odio, el instinto de crueldad. Los niños, los viejos y las mujeres no hacen la guerra,

\footnotetext{
3 “Contaminación”, Diccionario estrafalario, pág. 36.

4 “Animales", Diccionario estrafalario, pág. I4.

5 Gloria Fuertes, Diccionario estrafalario, pág. I7.
} 
pero mueren en ella

en los pueblos, en las ciudades,

mueren de sed, hambre o heridas de metralla.

Cuando todo el mundo se haga pacifista

se acabarán las guerras.

¡Quereos” (...) (Pon aquí el taco que quieras).

Sabemos que nos tenemos que morir.

¡Pero no todos al mismo tiempo(...)!(Aquí otro taco) ${ }^{6}$.

De ahí la definición del término antagónico paz:

La paz es lo mejor que puede suceder a un pueblo,

a un país, a una persona.

Tener paz es comprender y querer

al amigo, al familiar, al vecino.

Tener paz interior

es quererte, cuidarte, estar a gusto contigo,

y así surge el estar a gusto con todo el mundo.

Familias, pueblos, países,

si se quieren entre ellos

hacen la paz?

Su reflexión sobre los personajes dolientes, los que viven con el dolor y la soledad a cuestas (como ella misma durante muchos años) la invita siempre a hacérnoslos sentir "desde su propia ternura, desde un mundo tan peculiar como el suyo, donde solo un hilo delgadísimo separa la risa del llanto"?.

Ella tenía y la explicó, su propia idea de lo que quería hacer: "gritar a los sordos, hacer hablar a los mudos, alegrar a los tristes, poner mi verso en el hombro de los enamorados, hacer pensar a los demasiado frívolos, describir la belleza a los ciegos de espíritu, amonestar a los injustos, divertir a los niños"9.

Pero no ignoraba que entre los niños pueden darse casos de abusos. No se ocupa del bullying como tal, término desgraciadamente de moda en lugar de acoso. Pero sabe que existen niños que se comportan mal con otros, niños o adultos. Convertida en educadora social, con toques de brujilla simpática o hada madrina al acecho, rechazó la violencia de las pandillas de muchachos violentos en "La panda de los mocosos":

\footnotetext{
6 “Guerra”, Diccionario estrafalario, pág. I7.

7 "Paz", Diccionario estrafalario, pág. II5.

${ }^{8}$ Luzmaría Jiménez Faro, «Presentación », en G. Fuertes, Pecábamos como ángeles, M., Torremozas, I997, pág. 9.

9 G. Fuertes, « Medio siglo de poesía de Gloria Fuertes o vida de mi obra », en G. Fuertes, Obras incompoletas, pág. 30 .
} 
La panda de los mocosos

era el terror del parque.

Era una panda de enanos

(no eran enanos,

Eran pequeños de siete a doce años).

No eran enanos, eran hermanos.

Todos los días

hacían sus fechorías.

Con sus patines de ruedas,

empujar a las abuelas,

romper farolas,

dar pelotazos

a las señoras.

Y su favorita travesura

volcar los cubos de la basura.

Al más tranquilo y cariñoso

de los hermanos horrorosos

le pregunté: -¿Por qué te llaman

"El Campana"?

-Porque soy tontín, ton, tín.

MORALEJA: -Que la gente aprenda, que el bueno no es tonto,

es gente estupenda ${ }^{\mathrm{IO}}$.

No se conformaba con lo que veía a su alrededor. Si no le convencía o le desagradaba, procuraba contarlo para despertar conciencias, para implicar a quienes tenían en sus manos llevar a cabo algún cambio en la sociedad.

Advirtió los problemas de exclusión social que se daban en la sociedad de su momento. Cualquier niño rechazado por sus compañeros, por el entorno, por la sociedad, en suma, encontraba en ella a su gran valedora. Así se advierte en "Paco Pica, el niño ajo", antonomasia de los niños que huelen mal por falta de aseo o por otra circunstancia:

Io Versos fritos, págs. $3^{8-} 39$. 
Paco Pica, el niño ajo,

tenía cara de ajo,

ojos de ajo,

dientes de ajo

y pelos de ajo.

Nació en una huerta

que hay a la vuelta

del corral.

Paco Pica, el niño ajo,

fue a la escuela con trabajo.

-Este niño huele a ajo,

-decían sus compañeros

(no estaban bien educados,

todos le daban de lado).

Solo la niña Cebolla

se sentaba en su pupitre.

La maestra Cebolleta

se da cuenta,

y les regaña muy lenta.

LA MAESTRA:

-Yo quiero aquí al niño sano, que quiera al niño negrito, que quiera al niño africano, que quiera al niño cojito y que quiera al niño ajo. Además de compañeros, aquí todos sois hermanos. (La maestra Cebolleta, era "guay" у muy poeta)".

Ella entendía el amor en forma positiva, activa, no se conformaba con seguir la corriente, por más que la corriente fuese mayoritaria en determinado aspecto de la vida o de la opinión:

II Id., pág. 24 . 


\title{
LA GENTE DICE
}

\author{
La gente dice: \\ "Pobres tiene que haber siempre» \\ y se quedan tan anchos \\ tan estrechos de miras, \\ tan vacíos de espíritu, \\ tan llenos de comodidad. \\ Yo aseguro \\ con emoción \\ que en un próximo futuro \\ sólo habrá pobres de vocación ${ }^{12}$.
}

Algo muy parecido escribió al definir el término "pobre” para sus jóvenes lectores, porque el fondo, fuera quien fuese el destinatario, era idéntico:

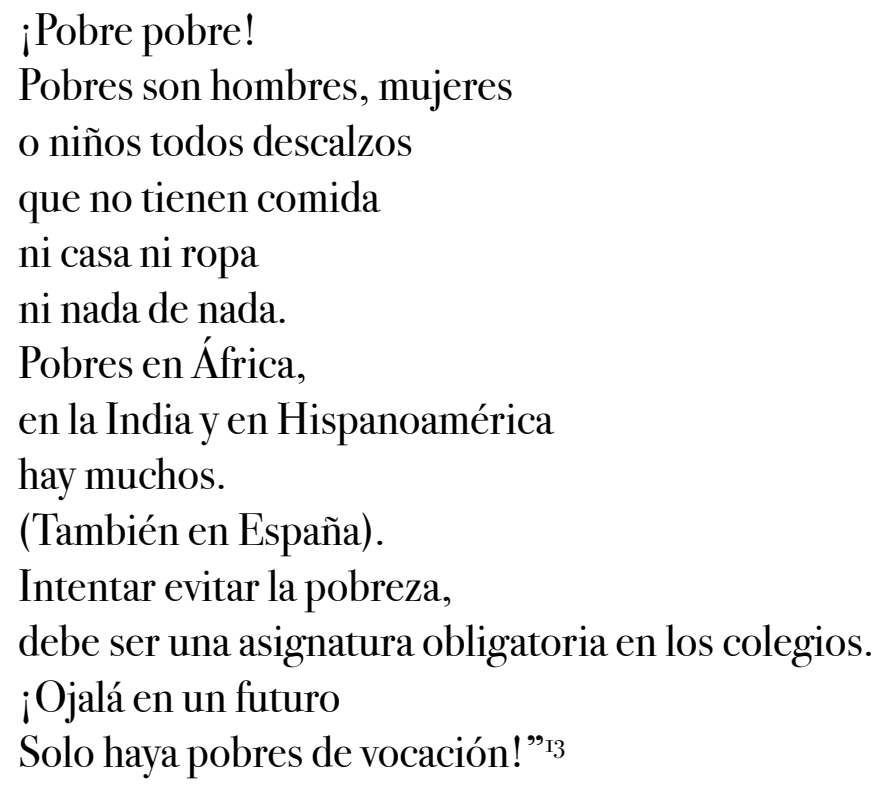

Claro que ella sabía muy bien que existen ricos y pobres. Pero no quiere engañar a nadie. Con palabras sencillas, como quien no quiere decirlo, afirmará sobre el dinero:

\footnotetext{
I2 G. Fuertes, Mujer de veso en pecho, M., Cátedra, I995.

I3 "Pobre", Diccionario estafalario, pág. I2I.
} 
Moneda o billete con el que se compra de todo.

Quien tiene mucho dinero se llama rico.

El rico tiene la obligación de dar lo que le sobre,

al pobre.

Si lo hace, el rico para a ser santo ${ }^{\mathrm{I} 4}$.

Gloria Fuertes, mujer creyente a su modo, dejaba caer alguna perla -a veces entre paréntesis, como se advirtió antes- en sus textos para los menores en edad, a quienes alertaba sobre este mundo desproporcionado, donde un gran número de seres humanos disfrutan de casi todo, mientras muchos millones de semejantes, apenas tiene para comer. Sabe que Dios está en todas partes, y que si el rico comparte lo que tiene con los demás se hace santo. Pero también sabe que eso ocurre pocas veces:

Dios es lo mejor del mundo.

No se le ve, pero se le siente.

Está en todas partes.

Está en todas las personas.

En todos los lugares de la Tierra,

del mar,

del universo.

Está en el pueblo, en la playa,

en la ciudad, en el monte,

en la casa del pobre

(a veces en la casa del rico),

en las iglesias,

y siempre

en el corazón de los niños

y de la gente buena.

Quien a Dios tiene,

nada le falta

(decía la santa). ${ }^{5}$

A ese Dios se dirigía, y su tono es semejante al de Lope de Vega, otro madrileño que también hablaba con Dios para contarle cómo iba el mundo y cómo le iba a él entre los seres del mundo. Gloria tiene hilo directo con Dios, y establece con Él una relación de tú a tú, reconociéndolo en cualquier lugar del Universo, como hace en su poema "Oración":

I4 “Dinero", Diccionario estafalario, pág. 44.

I5 “Dios”, Diccionario etrafalario, pág. 44. 
Que estás en la tierra Padre nuestro, que te siento en la púa del pino, en el torso azul del obrero, en la niña que borda curvada la espalda, mezclando el hilo en el dedo.

Padre nuestro que estás en la tierra, en el surco, en el huerto, en la mina, en el puerto, en el cine, en el vino, en la casa del médico.

Padre nuestro que estás en la tierra, donde tienes tu gloria y tu infierno y tu limbo que está en los cafés donde los pudientes beben su refresco.

Padre nuestro que estás en la escuela de gratis, y en el verdulero,

y en el que pasa hambre, y en el poeta, ¡nunca en el usurero!

Padre nuestro que estás en la tierra, en un banco del Prado leyendo, eres ese Viejo que da migas de pan a los pájaros del paseo.

Padre nuestro que estás en la tierra, en el cigarro, en el beso, en la espiga, en el pecho de todos los que son buenos.

Padre que habitas en cualquier sitio. Dios que penetras en cualquier hueco, tú que quitas la angustia, que estás en la tierra, Padre nuestro que sí que te vemos, los que luego te hemos de ver, donde sea, $\mathrm{o}$ ahí en el cielo ${ }^{\mathrm{I}}$. 
Gloria Fuertes, sellada como la poeta de los niños, no se quedó en la poesía risueña, alegre, juguetona, de relaciones fáciles entre las palabras, con personajes incontaminados, edénicos (niños, animales, naturaleza incontaminada). Fue siempre, también en su poesía para los de menor edad, una poeta inconformista, y nunca dejó de tocar algún tema comprometido. Una poeta social, en suma, que además de conducir al descubrimiento de lo « real maravilloso » que se disimula en la experiencia cotidiana, las técnicas « irracionalistas » de la poesía de Gloria Fuertes se orientan en la línea del testimonio y la denuncia », como advierte María Payeras Grau ${ }^{17}$. Por eso su poesía no es en absoluto superficial. Tanto en la poesía para adultos como en su obra para niños late un sentimiento profundo de hermandad con todos los seres de la Tierra, en especial con los menos afortunados: encuentra en ellos una especial paridad, porque ellos sufren en sus carnes y en su espíritu la sensación de soledad, de abandono, que siempre la acompañó. Gloria Fuertes, poeta social, sí, mujer comprometida, también.

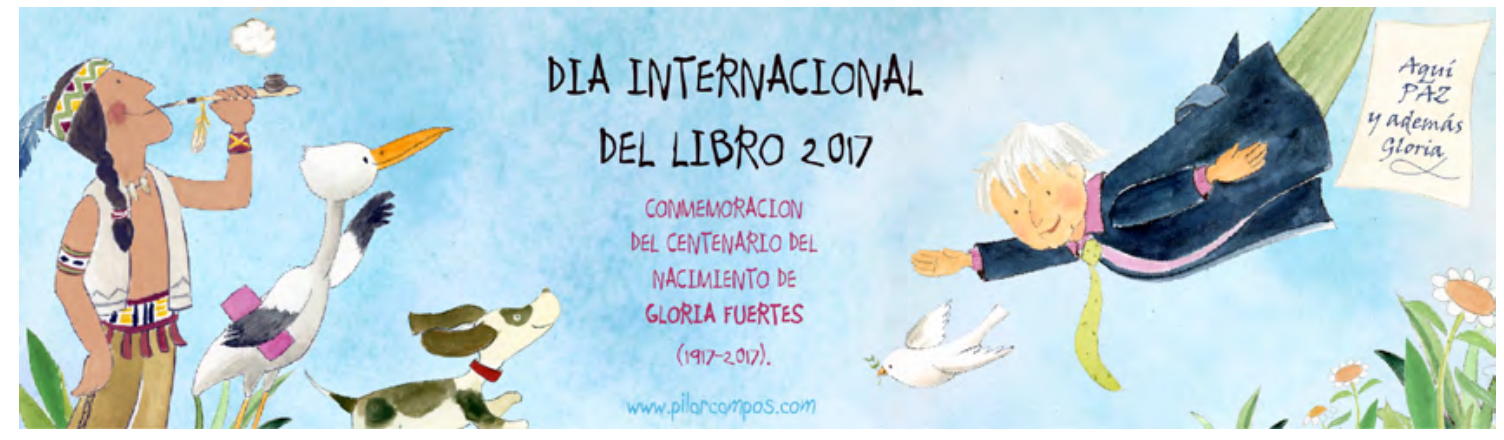

I7 “Escritoras bajo el franquismo”. Poesía, I939-I959, en AA.VV., Mujer y literatura en el siglo XX, Málaga, Centro Cultural de la Generación del 27, 2006, pág. $7^{2}$. 